Miguel de Valencia

\title{
Glosas de la cultura actual
}

En las antiguas mitologías se producían hechos extraordinarios. Los dioses alternaban con los mortales. En más de una oportunidad prendió entre ellos el amor carnal. Fruto de la unión de dioses y mortales fueron los héroes, seres que habían de sorprender con sus fabulosas hazañas.

Con frecuencia, por los senderos de alguna floresta deambulaban los centauros, amalgama de hombre y bruto. Sus correrías, sus galopes llenaban de espanto a las ninfas.

El tiempo y el fluir de otras culturas hicieron desaparecer tales maravillas, borrando de las fértiles imaginaciones la posibilidad de concebir lo imposible con todas sus consecuencias.

En nuestros días, los estudios históricos se centran en algunas ideas, fantásticas en apariencia. Detrás de los mitos yacen realidades que nos van entregando recursos para entender de qué manera se constituyeron los pueblos de la antigüedad. El significado de héroes y centauros se confronta con determinadas leyendas inspiradas en hechos concretos. Descubrimientos recientes enriquecen nuestro conocimiento sobre el próximo oriente. Por ejemplo, se han descifrado los jeroglíficos hititas y una de las escrituras cretenses, precisamente la denominada "linear", medio de expresión de un dialecto hablado en Grecia mil cuatrocientos años antes de nuestra Era. Y esto quiere decir que mucho antes de Homero ya se hablaba griego por las ri- 
beras del Mediterráneo. Tal vez, entonces, ya habían iniciado sus correrías los héroes y centauros, recogiendo, en sus andanzas, algunas realidades de tipo histórico.

A estos descubrimientos se agregan otros no menos interesantes. Nos referimos al hallazgo de unos manuscritos árabes y hebreos que entregan nuevas luces sobre el mundo de las viejas sectas religiosas judías de Palestina, allá en los comienzos de la Era Cristiana, y en un clima espiritual que conociera la dulce palabra de Jesús.

Sin duda las investigaciones arqueológicas tienen la virtud de esclarecer matices del mundo antiguo y de unas formas de vida cuya herencia se proyecta sobre los hechos actuales, sobre la filosofía y la religión. Ninfas y ondinas, dioses, héroes y centauros son reminiscencias de un mundo lleno de bellas ilusiones.

\section{*** *}

Se ha dicho que de Van Dick descienden los retratistas ingleses, creadores de la perfecta imagen aristocrática, tales como Gainsbourough y Reinolds. Ahora se habla de un estilo Gainsbourough, aplicado al delicado arte de vestir a las mujeres. $Y$ he ahí que los modistos se aplican a estudiar los cuadros del pintor inglés, del artista que plasmara retratos de gracia incomparable, colocados en el fondo de paisajes armoniosos, sus contornos fundidos en lírica orquestación.

Son famosos los retratos de la duquesa de Devoshire y de Mrs. Graham. En ellos la fragilidad femenina desaparece entre grandes lazos, flores exóticas, sombreros de anchas alas. Claro está que los bustos entregan su gracia y turgencia debido a los generosos escotes.

El estilo Gainsbourough ha iniciado su batalla. Muy pronto sabremos que las féminas se visten a imitación de aquellas ladys inglesas, que simulaban desmayos entre flores y livianas farándulas.

Pero he ahí que la glosa de este fenómeno tiene un alcance de tipo histórico y estético. En efecto, no es la primera vez que los creadores de la moda tienden su vista acuciosa sobre las grandes obras de arte. Ya en la antigüedad, las mujeres griegas copiaron el peinado 
e indumentaria de una desconocida belleza, es decir, de aquella "parisién" que fuera intuida por los artistas egeos. $\mathrm{Y}$ el vestuario, como tema pictórico del Renacimiento, se proyectó a lo largo de alguna centuria. Las mujeres copiaban los miriñaques esbozados de alguna matrona renacentista. En nuestros días, después de la lucubraciones de Marinetti, Picasso y Dalí, se orienta la moda de acuerdo con los cánones de los retratistas ingleses del siglo XVIII. Un bello álbum, editado por una asociación internacional de modistos, recoge el movimiento pendular de la moda, del vivir femenino. $\mathrm{Y}$ al socaire de estas oscilaciones, no exentas de contenido social y estético, nos es dado el prodigio de tejer fantasías en torno al precepto bíblico de vestir al desnudo, frase que encierra un caudal de sentimentalismo constructivo y de sedimentación espiritual.

***

Con motivo de un reciente Congreso Internacional de Arquitectura, se ha vuelto a suscitar el tema de la arquitectura precolombina, sus características y su vinculación con los actuales tipos de construcción hispanocolonial.

La vivienda como necesidad y como expresión artística fue estudiada y resuelta en la época gloriosa de los mayas. He ahí un pueblo precursor del sentido arquitectónico de América. La casa fue para ellos una especie de máquina para vivir. Así lo atestiguan las ciudades inutilizadas y desérticas de Copán, Palenque y Tikal.

Los mayas edificaron pirámides con santuarios elevados. Para llegar hasta ellos fue necesario construir atrevidas escaleras, ornadas de estatuas realistas. De vez en cuando reproducían la imagen de dioses terribles, dibujaban algunas máscaras plenas de un sentido esotérico.

Brillan después en América los toltecas, pueblo deportista. Eran diestros jugadores de pelota. $\mathrm{Y}$ construyen campos de juego, frontones, especies de circos para los sacrificios humanos. En sus palacios 
hubo decoraciones fastuosas. Con frecuencia, se repite el motivo de la "Serpiente emplumada", representación del dios Quetzacoatl.

Los aztecas levantan sus edificios sobre islotes, comunicados entre sí por malecones de piedra. Sus casas eran de gran solidez. Muros y techos se levantaban y se tendían mediante enormes piedras sillares. Quizás de este tipo de vivienda se derivan las actuales construcciones hispanocoloniales mexicanas.

Pero los Incas, creadores de la gran civilización prehispánica, trazan calles, aljibes, parques y fortificaciones, con bastiones angulares. Fueron maestros en el corte de las piedras. Ejemplo de su arquitectura colosal es el Templo del Sol, en Cuzco. Muchas de sus casas fueron excavadas en las rocas, resistiendo el paso de los siglos.

Ahora bien, cuando llegan los conquistadores españoles traen sus elementos constructivos. Pero se encuentran con edificaciones de gran solidez, no exentas de una gracia primitiva. Y de la combinación de todos esos factores, indígenas e importados, surge el colonialismo de la vivienda. Por esta razón algunas de esas casas son como una copia de otras que existen en los rincones de España. Por ejemplo, la típica barraca valenciana parece renacer entre los muros blancos y los techos frágiles de las casas de campo de América. Y en las regiones frías se copia la solidez azteca y el barroquismo de las casonas del norte hispánico.

Toda una evolución del vivir se tiende a lo largo de varios siglos, rebulle en esas "máquinas para vivir" que son las casas.

$* * *$

Desde que los hombres se dieron cuenta de la importancia de sus pensamientos, tuvieron la preocupación de comunicarlos, de hacerlos volar por el ancho mundo, esperando que alguien los encontrase bellos, aceptables. Y así nacieron los correos primitivos por tierra y por mar. Sus avatares, sus innumerables anécdotas, sirven para conocer los recovecos del alma humana, su afán de proyección sentimental.

Poco después, los paquebotes, los vagones postales cruzan los ma- 
res y los caminos de la Tièra. El uso de los llamados "tubos neumáticos" establece una fácil red de comunicaciones aéreas de las ciudades.

Las cartas llevarán, de uno a otro confín, noticias sentimentales, cifras de negocios, razonamientos galantes, discursos moralistas.

Pero habrá un hombre genial, Rowland Hill, que inventa la manera de cobrar por anticipado el precio de llevar y traer las misivas. El uso de la estampilla de correo se pone en marcha, tal vez el día $10^{\circ}$ de mayo de 1840 . Después será la eclosión del telégrafo, el tendido de cables submarinos y fluviales. También se escuchará a distancia el campanilleo del teléfono. La radiotelefonía inicia sus primeros pasos. El servicio fonopostal presta grandes servicios. Hasta que la telefotografía lleve de un lado para otro las borrosas o claras imágenes.

El sueño de las comunicaciones ha llegado a máximas perfecciones. Una noticia, un pensamiento, los resultados de plurales discusiones son lanzados al aire, llegan a los confines apartados. $\mathrm{Y}$ el mundo, ancho y ajeno, va reduciéndose, se achica hasta límites impensados.

En nuestros días se expande el sueño de las comunicaciones interplanetarias. El hombre quisiera develar ciertos misterios, buscando las respuestas en lugares que están más allá de su espacio habitual. La palabra a través del espacio busca lugares remotos, desea registrar vibraciones de ignotos lugares. La aspiración tiene viejas raíces. Ya en el siglo XVIII, se observaron manchas lumínicas en Venus. Los resplandores persistieron durante varios meses. Los observadores creyeron que tales ráfagas de luz eran señales de los habitantes de otros mundos. La ciencia se ha encargado de aventar tales fantasías. Sin embargo, subsiste esa predisposición anímica a enviar la palabra hasta los planetas que ondean sobre nuestras cabezas. En algunas oportunidades se han dirigido señales a sus astros que forman parte del cortejo solar. Jamás se ha recibido respuesta alguna. ¿Acaso el problema es insoluble? ¿La ciencia llegará a conclusiones originales? He ahí que en modernos tratados de telecomunicación, el problema sigue planteado. Lo que indica que las esperanzas todavía germinan en el corazón de los hombres. 
Con razón suficiente se ha dicho que la Pedagogía adviene en épocas de inquietud social. Tal puede ser el signo de nuestra situación. Como es lógico, los educadores y los psicólogos tienden su vista hacia la urgente necesidad de estructurar una valedera filosofía de la educación, que permita la orientación del hombre.

Los conceptos esenciales de las teorías pedagógicas tienen sus raíces en las corrientes filosóficas. La educación se ha desarrollado como una realidad social. Nuestra época es fecunda en movimientos pedagógicos. Cabe, por lo menos, citar tres corrientes, diversas en apariencia. De un lado, la que quiere vivificar la educación del individuo. De otro, la que aspira a renovar la concepción social de la educación. Y, finalmente, la que pretende darle un sentido activo y vital.

He ahí, las tres direcciones esenciales de la pedagogía moderna: individual, social y vital-pragmática. Su denominador común lo constituye la búsqueda incesante de bases filosóficas en donde asentar sus postulados y aspiraciones.

Existe una Pedagogía Filosófica que tiene la virtud de englobar diversas aspiraciones. Sus ramas se conocen con los siguientes nombres: Pedagogía idealista de Gentile, Wineken y Foerster; Pedagogía de los Valores de Cohn, Messer y Häberlin; Pedagogía científicoespiritual de Dilthey y Litt, y Pedagogía Cultural de Spranger y Nohl.

Ahora bien, en esta búsqueda de una filosofía de la educación tiene suma importancia la llamada Pedagogía científico-espiritual. El nombre de Guillermo Dilthey resume, recientemente, uno de los períodos más gloriosos. Filósofo y tratadista de estética, aplicó a la Pedagogía sus originales intuiciones filosóficas.

En su obra Historia de la Pedagogía nos dice que la historia de la educación depende de dos factores esenciales: el progreso de la ciencia y el estado cultural de un pueblo o generación, que determi- 
na el ideal educativo. "Este ideal de educación se halla en relación íntima con el ideal de vida de la sociedad que educa. Así, la educación y los sistemas de enseñanza tienen que crecer, llegar a madurez y morir con los pueblos mismos". Una de sus más enérgicas afirmaciones dice: "Ninguna teoría de la educación del mundo podrá impedir el hundimiento de un sistema de educación en un pueblo que se hunde".

Posiblemente, la voz de Dilthey sigue clamando en medio de algunos desiertos humanos.

Traductores egipcios anuncian la edición plurilingüe de las poesías de Ibn Zamrak, el poeta de la Alhambra, del siglo XIV de nuestra Era. He ahí una labor de suma importancia, dadas las calidades estéticas de tan egregio poeta. Con frecuencia, los eruditos nos han dicho que después de la muerte de Ibn Zamrak, la poesía arábigoandaluza iniciará un descenso evidente.

Zamrak compuso cassidas oficiales de felicitación al monarca en toda clase de fiestas, en la circuncisión de los reales vástagos. Su obra es una especie de "Rimado de Palacio" con las distancias necesarias. Como en la obra del Canciller, nos entrega preciosos informes sobre determinados jirones del vivir oficial. Sus poesías son cassidas, epigramas y muwassahas. El poeta fue siempre dueño de su arte. Sabía desplazar ligeramente la melodía para conseguir efectos que no desdeñarían los parnasianos occidentales. Fue el último gran poeta árabe-andaluz. Cuando los ecos de sus poesías comenzaban a desfallecer, se preparaba la eclosión del Renacimiento. La "itálica manera" se introduce en momentos oportunos para llevar a cabo una gran revolución estética. Cambiar de raíz el alma y los cánones formales de la poesía española.

La traducción plurilingüe de los poemas de Zamrak tiene un delicado valor documental en los arabescos poéticos. 